\title{
CARACTERÍSTICAS AGRONÔMICAS E PRODUTIVAS DE CULTIVARES DE SOJA TRANSGÊNICAS
}

\section{AGRONOMIC AND PRODUCTIVE CHARACTERISTICS OF TRANSGENIC SOYBEAN CULTIVARS}

\author{
Rogério Farinelli ${ }^{1}$, Felipe Fontes Breschi ${ }^{1}$, Gabriel Queiroz Assunção ${ }^{1}$ \\ ${ }^{1}$ Centro Universitário da Fundação Educacional de Barretos (UNIFEB), Avenida Professor Frade Monte, 389. \\ CEP 14783-226, Barretos, SP.
}

\begin{abstract}
Resumo
Um dos principais fatores para o aumento da produção de soja no Brasil é o desenvolvimento de novas cultivares, tornando-se indispensável à avaliação do desempenho e desenvolvimento destas, para facilitar a recomendação de forma adequada para cada região. Diante do exposto, o trabalho teve como objetivo oferecer informações sobre o desempenho agronômico de cultivares comerciais de soja transgênica (RR e IPRO) para a região de Barretos-SP, na safra 2015/2016. O experimento foi conduzido em delineamento experimental em blocos ao acaso, com 11 tratamentos (cultivares de soja RR e IPRO) com 4 repetições. Durante o experimento foram avaliadas: florescimento pleno, maturação fisiológica, área foliar, número de ramificações por planta, altura de planta e de inserção da primeira vagem, número de vagens por planta, número de grãos por vagem, massa de 100 grãos, produtividade e análise de correlação simples entre as características agronômicas. Os dados foram submetidos à análise de variância, pelo teste $\mathrm{F}(\mathrm{p}<0,05 \%)$. O maior valor para a área foliar foi apresentado pelas cultivares DM 6563 IPRO e BMX Potência RR, que também se destacaram para o número de vagens por planta, seguidas por CD 2728 IPRO, NA 7338 RR, NA 7337 RR e NK Coker 7.5 RR. Já a NA 7337 RR e NK Coker 7.5 RR obtiveram os resultados mais significativos para o número de ramificações. A BMX Ponta IPRO apresentou a maior massa de 100 grãos, seguida da NA 7738 IPRO. A cultivar BMX Potência RR obteve melhor desempenho agronômico devido à área foliar e número de vagens por planta, propiciando maior produtividade. Quanto às correlações, valores positivos foram alcançados entre a matéria seca e ramificações por planta, para ramificações e vagens por planta, como também para vagens por planta e produtividade de grãos.
\end{abstract}

Palavras-chave: Glycine max L., genótipos, biotecnologia, produtividade de grãos.

\begin{abstract}
One of the main factors for the increase of soybean production in Brazil is the development of new cultivars, making it indispensable to evaluate their performance and development, for facilitating the recommendation appropriately for each region. Thus, the objective of this study was to provide information on the agronomic performance of transgenic soybean cultivars (RR and IPRO) for the region of Barretos-SP, in 2015 and 2016 during the crop season. The experimental design was arranged in complete randomized blocks and 11 treatments (soybean RR and Intacta) with four replications. During the experiment were evaluated the following factors: number of days to flowering, number of days to maturity, leaf area, number of branches per plant, the plant height, the first pod insertion, number of pods per plant and grains per pod, the mass of 100 grains, grains yield and simple correlation analysis between the agronomic characteristics.
\end{abstract}

E-mail: rogerio.farinelli@unifeb.edu.br, 16-997099956 (autor correspondente)

Recebido para publicação em: 10/02/2019

Aceito para publicação em: 26/08/2019

https://doi.org/10.4322/1980-0029.072020 
Data were analyzed using the F test $(\mathrm{p}<0.05 \%)$. The highest value for the leaf area was presented by DM 6563 IPRO and BMX Power RR cultivars, which also stood out for the number of pods per plant, followed by CD 2728 IPRO, NA 7338 RR, NA 7337 RR and NK Coker 7.5 RR. However, the NA 7337 RR and NK Coker 7.5 RR obtained the most significant results for the number of branches. The BMX Ponta IPRO presented the highest mass of 100 grains, followed by the NA 7738 IPRO. The cultivar BMX Power RR obtained better agronomic performance due to the leaf area and number of pods per plant, providing the highest yield. Regarding the correlations, positive values were reached between dry matter and branches per plant, for branches and pods per plant, as well as for pods per plant and grain yield.

Keywords: Glycine max L., Genotypes, Biotechnology, Grains Yield.

\section{Introdução}

A soja (Glycine max (L.) Merrill) é considerada a mais importante oleaginosa do mundo e uma das mais importantes no Brasil, empregada tanto para consumo animal quanto na alimentação humana, com consumo in natura ou em produtos derivados.

Nesse contexto, a produção brasileira é promissora, pois a soja é a principal cultura em área e produção de grãos, situando o país como segundo maior produtor mundial e o primeiro exportador. A produção média da safra 2016/17 foi de 113,9 milhões de toneladas, em uma área total de cultivo de 33,9 milhões de hectares, destacando-se os estados de MT, PR, RS e GO (Companhia Nacional de Abastecimento, 2018).

Entre os fatores ambientais que exercem efeitos sobre o desenvolvimento da cultura da soja, os mais importantes são a umidade, a temperatura e o fotoperíodo, que variam entre as cultivares e de acordo com as diferentes épocas do ano. O potencial de rendimento da soja é determinado geneticamente, no entanto, o efeito dos fatores ambientais pode interferir na sua expressão, limitando o seu desenvolvimento em algum momento durante o ciclo da cultura (Empresa Brasileira de Pesquisa Agropecuária, 2013).

Para proporcionar rendimentos elevados de grãos, o ideótipo de planta de soja deve reunir: estatura de planta igual ou superior a $65,0 \mathrm{~cm}$; inserção das primeiras vagens superior a $10,0 \mathrm{~cm}$; resistência a doenças, insetos, pragas, nematoides, acamamento e deiscência; boa qualidade fisiológica da semente; adaptação às condições locais de ambiente e sistema agrícola; alta capacidade de extração de fósforo; além de tolerância a deficiências e excessos hídricos (Pires et al., 2005).

O aumento da produção nos últimos anos se deve principalmente à alta tecnologia empregada a essa cultura, sendo principalmente através do desenvolvimento de novas cultivares, no tocante ao melhoramento genético, com o surgimento de genótipos resistentes às pragas, doenças, plantas daninhas, garantindo melhor qualidade nutricional e mais adaptadas a diversas regiões do país.

Dentro dos programas de melhoramento genético da soja, o principal destaque é o uso da biotecnologia, com o surgimento da soja geneticamente modificada (soja transgênica). A primeira soja transgênica lançada comercialmente (Roundup Ready ${ }^{\circledR}$ - RR), obtida com a transformação genética de plantas por meio da engenharia genética, difere da soja convencional por possuir um gene que expressa resistência (gene cp4-epsps) ao herbicida de ação total não seletivo, denominado de glyphosate. A introdução desse gene facilitou o controle das plantas daninhas, e sua utilização se generalizou em algumas regiões, quando, ao mesmo tempo, surgiram reações com críticas à segurança dessa nova tecnologia (Empresa Brasileira de Pesquisa Agropecuária, 2018).

Outra tecnologia que vem crescendo no Brasil é a utilização de plantas geneticamente modificadas com a expressão dos genes da bactéria Bacillus turigienses (Bt), denominada Intacta $\mathrm{RR} \mathrm{PRO}^{\circledR}$, que confere à planta a produção de proteínas cristais (Cry), que por sua vez matam insetos-lagartas da ordem Lepidoptera, mais precisamente promovendo a solubilização do cristal, transformação para a forma ativa da protoxina, a ligação de alta afinidade com os receptores do intestino médio, a inserção, irreversível, da toxina na membrana e formação de poros. Estes poros causam a perda da regulação osmótica e lise da célula, ocasionando a morte do inseto. Dentre as lagartas, cuja tecnologia Bt controla, destacam-se a Anticarsia gemmatalis (Hübner, 1818) (Lepidoptera: Erebidae), a lagarta falsa-medideira Chrysodeixis includens (Walker, 1858) (Lepidoptera: Noctuidae), além do controle da largarta-da-maçã Heliothis virescens (Fabricius, 1781) 
(Lepidoptera: Noctuidae) e da broca-das-axilas Crocidosema aporema (Walsingham, 1914) (Lepidoptera: Tortricidae), além de sua tolerância aos herbicidas à base de glyphosate (Silva, 2013).

A utilização de tecnologias Roundup Ready ${ }^{\circledR}$ e a Intacta RR2 $\mathrm{PRO}^{\circledR}$ continua crescente entre os produtores e vem sendo o caráter de maior oferta pelas instituições de pesquisa, por meio das novas cultivares. Considerando a importância da soja RR e Bt para a produção brasileira e o desenvolvimento de novas cultivares, torna-se imprescindível estudar as características agronômicas das cultivares, assim como sua produtividade e adaptação para cada região.

Dessa forma, o objetivo do trabalho foi avaliar as características agronômicas e produtivas de cultivares comerciais de soja transgênicas (tecnologia Roundup Ready $^{\circledR}$ e Intacta ${ }^{\circledR}$ ) para a região de Barretos-SP, a fim de oferecer informações auxiliando o produtor na escolha correta das cultivares.

\section{Material e Métodos}

O experimento foi desenvolvido durante a safra primavera-verão 2015/2016, na área experimental localizada na Fazenda da Prefeitura Municipal de Barretos-SP, em Latossolo vermelho distrófico, apresentando latitude $20^{\circ} 33^{\prime} 26^{\prime \prime}$ Sul, longitude $48^{\circ} 34^{\prime} 04^{\prime \prime}$ 'Oeste e altitude de 530 metros. O clima da região, segundo a classificação de Köppen, é Aw, ou seja, com inverno seco e moderado, e verão quente e chuvoso, obtendo uma precipitação de $555 \mathrm{~mm}$ durante o ciclo da cultura, com média de $5,4 \mathrm{~mm}$ por dia.

No experimento foram avaliadas 11 cultivares de soja, todas modificadas geneticamente, sendo cinco cultivares somente com a tecnologia Roundup Ready ${ }^{\circledR}$ - RR, e seis cultivares contendo a tecnologia Intacta RR2PRO. As cultivares utilizadas foram: BMX Potência RR, BMX Ponta IPRO; BMX Solar RR (Brasmax), MSOY 6410 IPRO (Monsoy), NA 5909 RR, NA 7337 RR, NA 7338 IPRO (Nidera), DM 5936 IPRO, DM 6563 IPRO (Dom Mario), CD 2728 IPRO (Coodetec) e NK Coker 7.5 RR (IS Venezuela).

Os resultados da análise química do solo da área experimental, na profundidade de $0-20 \mathrm{~cm}$, apresentaram os seguintes valores: $\mathrm{pH}\left(\mathrm{CaCl}_{2}\right)=5,5$; M.O. $\left(\mathrm{g} \mathrm{kg}^{-1}\right)=26 ; \mathrm{P}\left(\mathrm{mg} \mathrm{dm}^{-3}\right)=3 ; \mathrm{K}\left(\mathrm{mmol}_{\mathrm{c}} \mathrm{dm}^{-3}\right)=3,4$; $\mathrm{Ca}\left(\mathrm{mmol}_{\mathrm{c}} \mathrm{dm}^{-3}\right)=28 ; \mathrm{Mg}\left(\mathrm{mmol}_{\mathrm{c}} \mathrm{dm}^{-3}\right)=13$; $\mathrm{H}+\mathrm{Al}\left(\mathrm{mmol}_{\mathrm{c}} \mathrm{dm}^{-3}\right)=24,9 ; \mathrm{SB}\left(\mathrm{mmol}_{\mathrm{c}} \mathrm{dm}^{-3}\right)=44,4$; $\mathrm{CTC}\left(\mathrm{mmol}_{\mathrm{c}} \mathrm{dm}^{-3}\right)=69,4 \mathrm{e} \mathrm{V}(\%)=64,0$.
O sistema de manejo de solo empregado foi o convencional, utilizando grade intermediária, subsolagem e duas gradagens niveladoras. Na adubação mineral, utilizou-se semeadora/ adubadora no espaçamento entre linhas de $0,50 \mathrm{~m}$, a fim de distribuir o adubo MAP (07-34-00) na dose de $180 \mathrm{~kg} \mathrm{ha}^{-1}$. A semeadura foi feita em 15/11/2015, de forma manual, distribuindo-se 25 sementes $\mathrm{m}^{-1}$, sendo que posteriormente realizaram-se os desbastes, deixando 18 plantas $\mathrm{m}^{-1}$ perfazendo uma população de 360 mil plantas ha ${ }^{-1}$.

No estádio R1 (início do florescimento) foi realizada a adubação de cobertura com $80 \mathrm{~kg} \mathrm{ha}_{-1} \mathrm{de}$ $\mathrm{KCl}$, de forma manual, a lanço.

O delineamento experimental utilizado foi o delineamento em blocos casualizados, constituindo-se de 11 tratamentos (cultivares) com quatro repetições. Cada parcela foi constituída por quatro linhas de 5 metros de comprimento, com espaçamento entre linhas de 0,50 metro, consideradas como área útil as duas linhas centrais e desprezando-se 0,50 metro de cada extremidade.

Depois da instalação do experimento, as parcelas de soja foram conduzidas de acordo com os procedimentos técnicos necessários, a fim de mantê-las livres da interferência de plantas daninhas, insetos-praga e doenças.

Durante o desenvolvimento das cultivares de soja foram realizadas as seguintes avaliações: Florescimento: número de dias compreendido entre a emergência das plântulas até $50 \%$ das plantas no estádio R1. Área foliar $\left(\mathrm{cm}^{2}\right)$ : determinou-se no estádio R2 (florescimento pleno) em três trifólios localizados no terço médio de dez plantas, utilizando a equação $\mathrm{AF}=\mathrm{C} \times \mathrm{L}$, onde $\mathrm{AF}$ é a área foliar, C é o maior comprimento do limbo foliar $(\mathrm{cm}) \mathrm{e}$ Lé a maior largura do limbo foliar (cm). Maturação fisiológica: número de dias compreendido entre a emergência das plântulas até $50 \%$ das plantas no estádio R8, ou seja, maturação plena.

No final do ciclo fisiológico, foram coletadas 10 plantas por parcela ao acaso na área útil, objetivando avaliar os componentes morfológicos e produtivos, que foram os seguintes: Número de ramificações por planta: fornecido pela contagem das ramificações totais e o número total de plantas da amostra. Altura de plantas $(\mathrm{cm})$ : determinou-se, utilizando régua graduada em centímetros, a distância compreendida entre a superfície do solo e a extremidade apical da haste principal de cada planta. Altura de inserção da primeira vagem $(\mathrm{cm})$ : 
determinou-se, utilizando régua graduada em centímetros, a distância do nível do solo (colo da planta) à inserção da primeira vagem. Número de vagens por planta: fornecida pela relação entre número total de vagens e o número total de plantas da amostra. Número de grãos por vagem: deu-se pela relação entre o número total de grãos e o número total de vagens. Massa de 100 grãos: determinou-se através da contagem de 2 subamostras de 100 grãos coletados ao acaso por parcela experimental, e a seguir realizaram-se as pesagens, com correção do teor de água a 13\%. Produtividade de grãos $\left(\mathrm{kg} \mathrm{ha}^{-1}\right)$ : realizou-se colhendo as plantas da área útil de cada parcela experimental com posterior trilha mecânica e pesagem dos grãos, sendo os dados obtidos transformados em $\mathrm{kg} \mathrm{ha}^{-1}$, a $13 \%$ de umidade determinado por meio do método da estufa a $105^{\circ} \mathrm{C} \pm 3^{\circ} \mathrm{C}$ por 24 horas (Brasil, 2009).

Os dados foram submetidos à análise de variância utilizando o teste $\mathrm{F}$, e as médias dos tratamentos comparadas pelo teste de Scott-Knott a $5 \%$ de probabilidade. Utilizou-se o software SISVAR, na versão 5.6 da Universidade Federal de Lavras - UFLA (Ferreira, 2011) O teste de média utilizado para comparação das cultivares teve por objetivo reunir os tratamentos em grupos. Através desse procedimento, formam-se grupos de médias mais definidos, e a interpretação dos resultados pode ser realizada com mais clareza.

\section{Resultados e Discussão}

$\mathrm{Na}$ Tabela 1 são apresentados os resultados referentes ao número de dias para o florescimento e maturação fisiológica. Os resultados mostraram que as cultivares M-SOY 6410 IPRO e BMX Potência RR obtiveram menor período para o florescimento (42 dias), porém não foram consideradas as de menor ciclo fenológico, que foi alcançado pelas cultivares BMX Solar RR e DM 6563 IPRO, seguidas por DM 5936 IPRO (103 e 105 dias, respectivamente).

Para o Estado de São Paulo, o ciclo fenológico da soja de até 120 dias é considerado como grupo de maturação precoce (Empresa Brasileira de Pesquisa Agropecuária, 2013). Sendo assim, independentemente dos valores encontrados, todas as cultivares analisadas se comportaram como de ciclo precoce (Tabela 1). Existe uma tendência na preferência dos produtores rurais pelas cultivares precoces, por permanecerem menos tempo no campo e assim possibilitarem o escape da ação do patógeno causador da ferrugem asiática (Espindola et al., 2008). Outro fator para a escolha de cultivares de ciclo precoce é a possibilidade do cultivo de milho na segunda safra (safrinha), ou até como é no caso de Barretos e região, o plantio de cana subsequente, tratando-se de área de reforma de canaviais.

Em relação à área foliar, as cultivares que se destacaram foram DM 6563 IPRO, apresentando

Tabela 1. Florescimento (FL), área foliar (AF), matéria seca da parte aérea (MS), maturação fisiológica (MF) e número de ramificações por planta (RM) de cultivares de soja transgênicas. Barretos, SP, 2016

\begin{tabular}{|c|c|c|c|c|c|}
\hline Cultivares & $\begin{array}{c}\text { FL } \\
\text { (dias após a } \\
\text { emergência) }\end{array}$ & $\frac{\mathrm{AF}}{\left(\mathrm{cm}^{2}\right)}$ & $\frac{\text { MS }}{\left(\text { g planta }^{-1}\right)}$ & $\begin{array}{c}\text { MF } \\
\text { (dias após a } \\
\text { emergência) }\end{array}$ & $\frac{\mathrm{RM}}{\left(\mathrm{n}^{0}\right)}$ \\
\hline BMX Potência RR & $42 \mathrm{c}$ & $41,9 \mathrm{a}$ & 6,2 & $120 \mathrm{a}$ & $4,3 b$ \\
\hline BMX Ponta IPRO & $44 a$ & $22,0 \mathrm{c}$ & 2,7 & $110 \mathrm{c}$ & $1,5 \mathrm{~d}$ \\
\hline BMX Solar RR & $43 b$ & $33,2 b$ & 4,4 & $103 e$ & $3,3 \mathrm{c}$ \\
\hline M-SOY 6410 IPRO & $42 \mathrm{c}$ & $34,1 b$ & 4,3 & $106 \mathrm{~d}$ & $3,5 \mathrm{c}$ \\
\hline NA 5909 RR & $43 b$ & $34,4 b$ & 6,5 & $106 \mathrm{~d}$ & $3,9 b$ \\
\hline NA 7337 IPRO & $43 b$ & $28,9 \mathrm{c}$ & 8,9 & $108 d$ & $5,1 \mathrm{a}$ \\
\hline NA 7338 IPRO & $43 b$ & $28,3 \mathrm{c}$ & 4,7 & $109 \mathrm{c}$ & $3,0 \mathrm{c}$ \\
\hline DM 5936 IPRO & $43 b$ & $37,4 b$ & 5,5 & $105 \mathrm{e}$ & $3,2 \mathrm{c}$ \\
\hline DM 6563 IPRO & $43 b$ & $47,1 \mathrm{a}$ & 5,7 & $103 e$ & $3,4 \mathrm{c}$ \\
\hline CD 2728 IPRO & $43 b$ & $27,1 \mathrm{c}$ & 4,4 & $114 b$ & $4,0 \mathrm{~b}$ \\
\hline NK Coker 7.5 RR & $43 b$ & $29,1 \mathrm{c}$ & 3,6 & $120 \mathrm{a}$ & $5,3^{\mathrm{a}}$ \\
\hline Teste F & $8,74 * *$ & $7,96 * *$ & $1,91 \mathrm{~ns}$ & $44,52 * *$ & $6,82 * *$ \\
\hline Média & 43 & 32,7 & 5,20 & 109 & 3,7 \\
\hline CV $(\%)$ & 0,86 & 13.91 & 46,55 & 1,64 & 21,54 \\
\hline
\end{tabular}

Médias seguidas de letras distintas diferem entre si pelo teste de Scott-Knott a 5\% de probabilidade. ${ }^{\text {ns }}$ não significativo,

$* \mathrm{e}^{* *}$ significativo a $5 \%$ e $1 \%$ de probabilidade pelo teste $\mathrm{F}$, respectivamente. 
o valor de 47,0 $\mathrm{cm}^{2}$, e a BMX Potencia RR com $41,9 \mathrm{~cm}^{2}$, possuindo assim uma das maiores áreas fotossintéticas no estádio R2 (Tabela 1). A área foliar retrata a capacidade fotossintética que a planta é capaz de apresentar, além de preservar sua integridade frente à incidência de patógenos e ataque de insetos-praga. Além disso, pode ser considerada uma importante ferramenta para estudar o comportamento de diferentes materiais genéticos, sendo que a maioria dos processos fisiológicos que afetam o rendimento de uma cultura está relacionada com esse caráter (Câmara \& Heiffig, 2000).

Quanto à matéria seca, os dados apresentados foram não significativos. Sendo assim, a cultivar que apresentou menor área foliar foi a mesma que apresentou menor valor médio em relação à matéria seca.

Para o número de ramificações por planta (Tabela 1), novamente destaca-se a BMX Potência RR, juntamente com a cultivar CD 2728 IPRO, sendo apenas superadas por NA 7337 IPRO $(4,3 ; 4,0$ e 5,1 ramificações por planta, respectivamente). Vale ressaltar que a cultivar BMX Potência RR não apresenta característica de resistência às lagartas desfolhadoras (gene $\mathrm{Bt}$ ), que acometem o limbo foliar, nervuras, além de pecíolos e órgãos reprodutivos.

Nunes et al. (2016), estudando o comportamento agronômico de diversas cultivares de soja transgênicas, obtiveram para esta mesma cultivar um dos maiores resultados para área foliar, destacando-se também pelo menor ciclo fenológico.

Em relação à altura de planta e altura de inserção da primeira vagem, os resultados obtidos pelas cultivares, bem como os valores médios do experimento, foram baixos, devido às ausências de condições climáticas ideais (temperatura e precipitação), afetando diretamente as cultivares por serem precoces e semiprecoces. Porém, no trabalho realizado por Souza et al. (2013) utilizando redutores de crescimento na soja, observou-se que as plantas de soja com menores estruturas têm sua arquitetura da planta mais ereta, fazendo com que ela se torne mais tolerante ao acamamento associado a um maior potencial de rendimento de grãos de soja.

Sendo assim, as cultivares que apresentaram uma maior altura de planta foram NA 7338 IPRO e BMX Potencia RR, com 55,8 e 51,0 cm de altura, respectivamente. Para a altura de inserção da primeira vagem, novamente a cultivar NA 7338 IPRO foi superior, apresentando $12,5 \mathrm{~cm}$ de altura, semelhante à cultivar BMX Ponta IPRO, apresentando o mesmo resultado (Tabela 2). Mesmo assim, o valor médio apresentado pelas maioria das cultivares ficou abaixo da média exigida pelos produtores rurais, o que dificulta a mecanização da colheita, pois, de acordo com Rezende \& Carvalho (2007), a altura de inserção

Tabela 2. Altura de planta (AP), altura de inserção de primeira vagem (AI), número de vagens por planta (NVP), número de grãos por vagem (NGV), massa de 100 grãos (MG) e produtividade de grãos (PROD) de cultivares de soja transgênicas. Barretos, SP, 2016.

\begin{tabular}{|c|c|c|c|c|c|c|}
\hline \multirow{2}{*}{ Cultivares } & AP & AI & NVP & NGV & \multirow{2}{*}{$\begin{array}{c}\text { MG } \\
\text { (g) }\end{array}$} & \multirow{2}{*}{$\begin{array}{c}\text { PROD } \\
\left(\mathrm{kg} \mathrm{ha}^{-1}\right)\end{array}$} \\
\hline & \multicolumn{2}{|c|}{----(cm)----- } & \multicolumn{2}{|c|}{------(n'0)----- } & & \\
\hline BMX Potência RR & $51,0 \mathrm{a}$ & $5,3 b$ & $67,2 \mathrm{a}$ & 2,4 & $14,1 b$ & $2.040 \mathrm{a}$ \\
\hline BMX Ponta IPRO & $46,7 b$ & $12,5 \mathrm{a}$ & $36,4 b$ & 2,3 & $16,9 a$ & $1.428 \mathrm{c}$ \\
\hline BMX Solar RR & $33,7 \mathrm{c}$ & $5,1 b$ & $39,1 b$ & 2,5 & $11,6 \mathrm{c}$ & $1.348 \mathrm{c}$ \\
\hline M-SOY 6410 IPRO & $40,8 \mathrm{c}$ & $5,8 b$ & $43,0 \mathrm{~b}$ & 2,5 & $12,7 \mathrm{c}$ & $1.229 \mathrm{~d}$ \\
\hline NA 5909 RR & $37,5 \mathrm{c}$ & $7,1 \mathrm{a}$ & $42,8 b$ & 2,3 & $15,1 b$ & $1.630 \mathrm{~b}$ \\
\hline NA 7337 IPRO & $39,6 \mathrm{c}$ & $6,8 \mathrm{a}$ & $58,2 \mathrm{a}$ & 2,5 & $14,3 b$ & $1.556 \mathrm{~b}$ \\
\hline NA 7338 IPRO & $55,8 \mathrm{a}$ & $12,5 \mathrm{a}$ & $51,8 \mathrm{a}$ & 2,3 & $16,6 \mathrm{a}$ & $1.762 b$ \\
\hline DM 5936 IPRO & $39,8 \mathrm{c}$ & $6,5 \mathrm{a}$ & $45,7 b$ & 2,5 & $14,6 b$ & $1.674 b$ \\
\hline DM 6563 IPRO & $36,5 c$ & $5,2 \mathrm{~b}$ & $56,1 \mathrm{a}$ & 2,5 & $14,1 b$ & $1.513 b$ \\
\hline CD 2728 IPRO & $37,5 \mathrm{c}$ & $5,3 b$ & $51,2 \mathrm{a}$ & 2,4 & $11,8 \mathrm{c}$ & $1.546 \mathrm{~b}$ \\
\hline NK Coker 7.5 RR & $46,8 b$ & $6,4 b$ & $61,7 \mathrm{a}$ & 1,6 & $11,7 \mathrm{c}$ & $1.372 \mathrm{c}$ \\
\hline Teste F & $12,1 * *$ & $23,44 * *$ & $2,28 *$ & $1,55^{\mathrm{ns}}$ & $8,97 * *$ & $2,85^{*}$ \\
\hline Média & 42,3 & 7,1 & 50,3 & 2,3 & 13,9 & 1.554 \\
\hline CV (\%) & 9,30 & 15,8 & 25,81 & 16,77 & 8,83 & 17,02 \\
\hline
\end{tabular}

Médias seguidas de letras distintas diferem entre si pelo teste de Scott-Knott a $5 \%$ de probabilidade. ${ }^{\text {ns }}$ não significativo, $* \mathrm{e}^{* *}$ significativo a $5 \%$ e $1 \%$ de probabilidade pelo teste $\mathrm{F}$, respectivamente. 
da primeira vagem adequada para a mecanização da colheita deve ser no mínimo de 10 a $12 \mathrm{~cm}$. Porém, para a maioria das lavouras de soja, a altura de inserção da primeira vagem mais satisfatória está em torno de $15 \mathrm{~cm}$, embora as colhedoras mais modernas possam efetuar a colheita com plantas apresentando altura de inserção em torno de $10 \mathrm{~cm}$ (Heiffig \& Câmara, 2006).

No trabalho realizado por Espindola et al. (2008) e Nunes et al. (2016), os fatores ambientais ou de práticas culturais que influenciaram na altura de planta influenciaram também na altura da inserção da primeira vagem, semelhante a este trabalho, em que todas as cultivares apresentaram baixa altura de planta e, consequentemente, baixa altura de inserção da primeira vagem. Já para Brandt et al. (2006), em experimento com diferentes sistemas de sucessão de culturas, a soja não apresentou diferenças em relação de alturas de plantas e inserção de primeira vagem.

Para o número de vagens por planta, a cultivar que se destacou apresentando o maior resultado foi novamente a BMX Potencia RR, com 67,2 vagens por planta (Tabela 2), contudo, para este componente houve outras que também se destacaram (NK Coker 7.5 RR, NA 7337 IPRO, DM 6563 IPRO, NA 7338 IPRO e CD 2728 IPRO). Para o número de grãos por vagem, não houve significância dos resultados, tendo média de 2,3 grãos por vagem (Tabela 2), corroborando Nunes et al. (2016), pois tal característica é fortemente influenciada pelo fator genético, onde nos programas de melhoramento mais modernos são selecionadas plantas de soja e genótipos a fim de produzirem 2 a 3 óvulos por vagem, sendo óvulos com maior massa e peso. (Navarro Junior \& Costa, 2002b). Não podendo ser comparada ao feijão, onde há uma grande variação de genótipos e cultivares que possuem a capacidade de formar de 4 a 7 grãos por vagem.

Souza et al. (2013), analisando a arquitetura de plantas e produtividade de soja, observaram que as plantas com menores estruturas apresentaram maior número de vagens, maior número de grãos por plantas e grãos mais pesados.

Os três principais componentes da produção da soja são o número de vagens por planta, número de grãos por vagem e massa dos grãos. Neste contexto, o número de vagens por planta está diretamente relacionado ao balanço entre a produção de flores por planta e a proporção destas que se desenvolvem. Para a produção de flores por planta, é necessário que haja flores por nó e nós por planta. Sendo assim, o menor porte ou estatura da planta de soja, como ocorrido no experimento, faz com que ela emita menos nós, e dessa forma poucas flores são formadas e fecundadas, originando assim menor número de vagens produtivas (Navarro Junior \& Costa, 2002a; Peixoto et al., 2000). Associado a isto, a disponibilidade hídrica no período reprodutivo e o fotoperíodo adequado também afetam a produções de flores, logo, maior número de vagens por planta.

Quanto à massa de 100 grãos, duas cultivares se destacaram, apresentando os maiores resultados (BMX Ponta IPRO e NA 7338 IPRO). Nunes et al. (2016) obtiveram o mesmo valor médio deste experimento. O peso das sementes é uma característica importante na parcela final: quanto maior a semente, maior será seu peso com menor número de sementes. Tal característica também tem influência direta na produtividade de grãos e é fortemente influenciada pelo ambiente de cultivo e sua interação com o genótipo. Tal fato pode ser notado para as cultivares NA 7338 IPRO e DM 5936 IPRO, que também apresentaram valores de massa de 100 grãos superiores à média geral, destacando-se também na produtividade de grãos (Tabela 2). Contudo, a BMX Potência RR, para a produtividade, foi superior entre as demais, apresentando o maior resultado (Tabela 2).

Mesmo assim, a produtividade média do presente trabalho foi inferior ao atual potencial das cultivares estudadas, pois houve a ocorrência de veranico e altas temperaturas principalmente durante os estádios R5 e R6 (enchimento de vagens). A disponibilidade de água é importante, principalmente em dois períodos de desenvolvimento da soja: germinação-emergência e floração-enchimento de grãos.

A necessidade de água na cultura da soja vai aumentando com o desenvolvimento da planta, atingindo o máximo durante a floração-enchimento de grãos (7 a $8 \mathrm{~mm} \mathrm{dia}^{-1}$ ), decrescendo após esse período. Déficits hídricos expressivos durante a floração e o enchimento de grãos provocam alterações fisiológicas na planta, como o fechamento estomático e o enrolamento de folhas, e, como consequência, causam a queda prematura de folhas e de flores e abortamento de vagens, resultando, por fim, em redução do rendimento de grãos (Empresa Brasileira de Pesquisa Agropecuária, 2013). 
Na Tabela 3 encontram-se os valores das correlações entre os componentes morfológicos, da produção e produtividade de grãos. Verificam-se doze correlações positivas, sendo mais significativos e de maiores amplitude entre a matéria seca da parte aérea e o número de ramificações, entre o número de ramificações e o número de vagens por planta e entre o número de vagens por planta e produtividade de grãos.

Tais resultados demonstram que o crescimento vegetativo da planta de soja propicia maior engalhamento e formação de ramos, os quais por sua vez permitem um maior número de nós reprodutivos presentes, onde se formam os racemos florais, que após a fecundação dão origem às vagens. Um dos componentes que afetam diretamente a produtividade da soja é a quantidade de vagens formadas, observadas no presente trabalho.

Segundo Navarro Junior e Costa (2002a), o rendimento de grãos de soja pode ser determinado, basicamente, pelo número de flores que cada

Tabela 3. Análises de correlação simples das características agronômicas das cultivares comerciais de soja transgênicas. Barretos, SP, 2016.

\begin{tabular}{cc}
\hline $\begin{array}{c}\text { Características } \\
\text { Agronômicas }^{1}\end{array}$ & Correlações \\
\hline AF x MS & 0,367 \\
AF x RM & 0,125 \\
AF x NVP & 0,362 \\
AF x NGV & 0,331 \\
AF x MG & $-0,134$ \\
AF x PROD & 0,324 \\
MS x RM & 0,575 \\
MS x NVP & 0,419 \\
MS x NGV & 0,391 \\
MS x MG & 0,096 \\
MS x PROD & 0,422 \\
RM x NVP & 0,692 \\
RM x NGV & $-0,347$ \\
RM x MG & $-0,501$ \\
RM x PROD & 0,176 \\
NVP x NGV & $-0,311$ \\
NVP x MG & $-0,179$ \\
NVP x PROD & 0,527 \\
NGV x MG & 0,185 \\
NGV x PROD & 0,145 \\
MG x PROD & 0,423 \\
\hline
\end{tabular}

${ }^{1} \mathrm{AF}=$ Área foliar; MS ; matéria seca da parte aérea; $\mathrm{RM}=$ número de ramificações por planta; $\mathrm{NVP}=$ número de vagens por planta; $\mathrm{NGV}=$ número de grãos por vagem; $\mathrm{MG}=$ massa de 100 grãos; $\mathrm{PROD}=$ produtividade de grãos. planta pode produzir e pela quantidade destas que se desenvolvem até vagens maduras e férteis. Também afirmaram que o número de vagens por planta e o de grãos por vagem são os dois componentes mais importantes no rendimento de grãos, pois a redução do número de grãos pode ser compensada pelo incremento destes, porém tal redução e consequentemente compensação não foram observadas, segundo a Tabela 3.

Em outro estudo, Navarro Junior \& Costa (2002b) concluíram que a importância relativa de cada componente da produção variou conforme cada cultivar testada. As diferenças encontradas entre as cultivares, quanto à produção de grãos por planta, sugerem que determinadas características tenham maior importância para a elevada produtividade de grãos da cultura da soja que outras. O que se assemelha nos resultados obtidos no presente trabalho.

\section{Conclusões}

A cultivar BMX Potência RR obteve melhor desempenho agronômico devido à área foliar e número de vagens por planta, propiciando maior produtividade. Quanto às correlações, valores positivos foram alcançados entre a matéria seca e ramificações por planta, para ramificações e vagens por planta, como também para vagens por planta e produtividade de grãos.

\section{Referências}

BRANDT, E. A., SOUZA, L. C. F., VITORINO, A. C. T., \& MARCHETTI, M. E. (2006). Desempenho agronômico de soja em função da sucessão de culturas em sistema plantio direto. Revista Ciência e Agrotecnologia, 30(5), 869-874.

BRASIL. Ministério da Agricultura. (2009). Determinação do grau de umidade. Regras para análise de sementes (398p.). Brasília: Ministério da Agricultura.

CÂMARA, G. M. S., \& HEIFFIG, L. S. (2000). Fisiologia, ambiente e rendimento da cultura da soja. In G. M. Câmara (Coord.), Soja: tecnologia da produção II (450 p.). Piracicaba: ESALQ/LPV.

COMPANHIA NACIONAL DE ABASTECIMENTO - CONAB. (2018). $4^{\circ}$ Levantamento de grãos da safra 2017/2018. 
Brasília: CONAB. Recuperado em 11 de junho de 2018, de http://www.conab.gov.br

EMPRESA BRASILEIRA DE PESQUISA AGROPECUÁRIA - EMBRAPA. (2013).

Tecnologias de produção de soja - região Central do Brasil-2014 (265 p.). Londrina: Embrapa Soja.

EMPRESA BRASILEIRA DE PESQUISA AGROPECUÁRIA - EMBRAPA. (2018).

Tecnologias de produção de soja - região central do Brasil - 2008 (280 p.). Londrina: Embrapa Agropecuária Oeste.

ESPINDOLA, S. M. C. G., BISINOTTO, F. F., FERREIRA JUNIOR, J. A., CUNHA, F. A. G., ALVES, G. A., RESENDE, V. O., \& HAMAWAKI, O. T. (2008). Avaliação do desempenho produtivo de linhagens de soja para a região do Cerrado. In Anais do Simpósio Internacional Savanas Tropicais II (pp. 7). Planaltina: Embrapa-Cerrados.

FERREIRA, D. F. (2011). SISVAR: a computer statistical analysis system. Ciência e Agrotecnologia, 35(6), 1039-1042.

HEIFFIG, L. S., \& CÂMARA, G. M. S. (2006). Soja: colheita e perdas (37p., Série: Produtor Rural). Piracicaba: ESALQ - Divisão de Biblioteca e Documentação.

NAVARRO JUNIOR, H. M., \& COSTA, J. A. (2002a). Contribuição relativa dos componentes do rendimento para produção de grãos em soja. Pesquisa Agropecuária Brasileira, 37(3), 269-274.

NAVARRO JUNIOR, H. M., \& COSTA, J. A. (2002b). Expressão do potencial de rendimento de cultivares de soja. Pesquisa Agropecuária Brasileira, 37(3), 275-279.

NUNES, H. D., FARINELLI, R., FERES, P. A., DIAS, G. J., \& TOBASI, I. L. (2016). Desempenho agronômico de cultivares de soja RR para a região de Barretos-SP. Ciência e Cultura, 12(12), 87-94.

PEIXOTO, C. P., CÂMARA, G. M. S., MARTINS, M. C., MARCHIORI, L. F. S., GUERZONI, R. A., \& MATTIAZZI, P. (2000). Épocas de semeadura e densidades de plantas de soja: I. Componentes da produção e rendimento de grãos. Scientia Agrícola, 57(1), 89-96.

PIRES, J. L. F. , COSTA, J. A., RAMBO, L., \& FERREIRA, F. G. (2005). Métodos para a estimativa do potencial de rendimento da soja durante a ontogenia. Pesquisa Agropecuária Brasileira, 40(4), 337-344.

REZENDE, P. M., \& CARVALHO, E. A. (2007). Avaliação de cultivares de soja (Glycine max (L.) Merrill) para o Sul de Minas Gerais. Ciência e Agrotecnologia, 31(6), 1616-1623.

SILVA, G. V. (2013). Efeitos de plantas Bt de soja e milho sobra pragas não-alvo e seus inimigos naturais. (Dissertação de mestrado). Universidade Federal do Paraná, Curitiba.

SOUZA, C. A., FIGUEIREDO, B. P., COELHO, C. M. M., CASA, R., T., SANGOI, L (2013). Arquitetura de plantas e produtividade da soja decorrente do uso de redutores de crescimento. Bioscience Journal, 29(3), 634-643. 